\title{
HISTORIA E «HISTORIA»: EN TORNO AL PROPUESTO «FIN DE LA HISTORIA»
}

\author{
Fernando M. Pérez Herranz \\ Universidad de Alicante
}

Si alguna vez un fantasma recorrio Europa', hoy ha tomado la vestimenta de un artículo periodístico ${ }^{2}$ que asusta a la mejor tradición historicista mundial. Quizá por un mecanismo psicológico defensivo: lo que sorprende en un momento determinado no es más que aquello que se está esperando desde hace mucho tiempo y cuya realidad se oculta por prudencia. El artículo de Fukuyama sobre «el fin de la historia" ha tenido la osadía de volver a la tesis denunciada por el materialismo histórico sobre el cambio. Así argumentaría, según Marx, el economista clásico: "[las relaciones de producción burguesa] son leyes eternas que deben regir siempre la sociedad. De modo que hasta ahora ha habido historia , pero ahora ya no la hay. Ha habido historia porque ha habido instituciones feudales y porque en estas instituciones feudales nos encontramos con unas relaciones de producción completamente diferentes de las relaciones de producción de la sociedad burguesa. que los economistas quieren hacer pasar por naturales y, por tanto, eternas"3. Ergo, para Marx, salir de la situación capitalista, exige la "realidad" de la historia. Pero Fukuyama da al traste con esta esperanza o utopía, porque esta realidad -la capitalista-liberal y por mor de su naturalismo- no genera historia.

Preguntémonos entonces: ¿Qué tipo de experiencia permite pensar, o no, la historia? Desde las ciencias, desde la Termodinámica, se nos dice: «el tiempo». Él es el que permite pensar los sistemas como irreversibles ${ }^{4}$. No todos lo son. Y las sociedades humanas, ¿son históricas? ¿sus procesos se dan como irreversibles? Magna cuestión para cuya respucsta, y por cautela, sólo nos cabe otra pregunta: ¿Tenemos experiencia de la irreversibilidad del «tiempo»? ¿Poseemos aquélla experiencia que hizo escribir a Kant: "Un hecho semejante [La Revolución Francesa] en la historia de la humanidad ya no se olvida, pues se ha descubierto en la naturaleza humana una disposición y capacidad para el bien, que ningún político hubiera podido deducir"?".

El escrito de Fukuyama nos ha respondido negativamente. Ante movimientos sociales, políticos y económicos de gran envergadura, experimenta lo inverso que

\footnotetext{
${ }^{1}$ MARX,K. \& ENGLiLS,F.: El manifiesto comunista, ed. Alhambra, Madrid, 1985, p.48.

${ }^{2}$ FUKUYAMA.F: "BI fin de la historia" en Claves, $n^{\circ} 1$, pp. 85-96. El articulo original es: "The End of History?", The National Interest. Washington, verano de 1989.

${ }^{3}$ MARX,C.: Miseria de la filosofia, ed. Progreso. Moscú. 1974, p. 98.

${ }^{4}$ Cfr., v. gr.. PRI(iOGiNE.I. \& STENCitRS.I.: La nueva alianza, Alianza Editorial. Madrid. 1983.

${ }^{5}$ KANT.I.:El conflicto de las facultades, It' parte.
} 
Kant: el «fin de la historia». Pero una experiencia de este tipo no es una mera opinión, un simple comentario, mejor o peor fundado, ni siquiera una creencia -de reducirlo al mundo ideológico de Fukuyama poco podría interesarnos- porque el texto que comentamos está internamente articulado, y, nos atreveríamos a decir, de forma cuasi-escolástica.

(i) En primer lugar, manifiesta su asombro por el acontecimiento más destacado del decenio de los ochenta: el fin de la Guerra Fría. Pero, en vez de congratularse, o escandalizarse, busca un marco conceptual en el que integrar ese acontecimiento. ¿Es un «drama» ad maiorem dei gloriam? ¿Es el resultado de contradicciones históricas? ¿Es puro azar? Sólo podremos saberlo sometiéndolo al concepto que permita pensarlo: La historia de la humanidad se caracteriza por la lucha (¿drama? ¿negaciones?) entre distintos sistemas político-jurídico-económico-sociales y uno de ellos ha resultado vencedor: el liberalismo frente al absolutismo, el comunismo, el fascismo, el tercermundismo. Triunfo que no es meramente pasajero, sino esencial, puesto que conduce a un Estado Homogéneo Universal.

(ii) En segundo lugar. la tesis de que este estado sea el de la Democracia Liberal Occidental es argumentada desde posiciones que llamaremos atributivas ${ }^{6}$. Esto es lo extraordinariamente valioso. (a) En general, tanto el modelo capitalista como el comunista utilizan modelos distributivos de justificación en beneficio de sí mismos. Dentro de una tradición cristiano-idealista, se supone que la Cultura, la Civilización, la «Gracia», se reparte «distributivamente» por entre los individuos. Proceso bajo el cual se convierten en personas al modo como Prometeo distribuyó la "política» en el diálogo platónico ${ }^{7}$. En los modelos distributivos se requiere de un mediador que evite la hipótesis de un Dios «dador de sentido» directamente. Así se configura la

\footnotetext{
${ }^{6}$ Llamaremos todo atributivo aquél cuyas partes están dadas disyuntivamente y lo que se dice del todo no tiene por qué decirse de cada una de las partes. Éstas se acumulan y las relaciones que establecen entre sí son asimétricas. Valga como ejenplo lo que PRESEDO dice en Historia 16, sobre cómo representaban el cuerpo humano los egipcios: "un agregado de partes: cabeza, hombros, manos, cintura, pies, etc., cada parte o aspecto será tratado en su forma más característica, distinta y clara, sin preocuparse (o sin poder expresarlo) de una unidad superior". Una totalidad distributiva es aquella cuyas partes están dadas conjuntivamente y lo que se dice del todo se dice de cada una de sus partes. Lo ilustra el conjunto de monedas del mismo cuño.

Estos todos no se dan aislados; cuando sobre una totalidad atributiva que suministra el componente material se desarrolla una totalidad distributiva tenemos una clase combinatoria. V. gr., sobre clases distributivas, ser de una raza, nacer en una nación. pertenecer a una religión..., se unen determinadas notas: negro (y no blanco o amarillo), africano (y no europeo, americano), musulmán (y no cristiano, hindú)... $\mathrm{Si}$, al contrario, sobre una clase atributiva se desarrolla una distributiva, tenemos una clase porfiriana. V.gr., los derechos del Hombre y del Ciudaddano de 1789. Se acumulan los articulos, art. 1: "Los hombres nacen y permanecen libres e iguales en derechos...". Art. 2: "La finalidad de toda asociación política...". Art. 3, Art. 17... Ahora se distribuyen por todos los hombres. Véase G.BUENO: "Operaciones autoformantes y heteroformantes" en El Basilisco, $\mathrm{n}^{2} \mathrm{~s} .7$ y 8, $\mathrm{I}^{\mathrm{P}}$ época, 1979.

${ }^{7}$ PLATÓN: El Protágoras, $320 \mathrm{c}-323$ a. " ¿También el sentido de la justicia y de la moral lo infundo así entre los hombres, o lo distribuyo entre todos?"/"Entre todos -dijo Zeus- y que todos participen. Pues no existirian las ciudades si participaran sólo unos pocos de entre ellos, como sucede en los otros saberes técnicos. Incluso, sí, dales de mi parte una ley: que al que no sea capaz de participar de la moralidad y la justicia le maten como a una enfermedad de la ciudad".
} 
imagen de un "pueblo elegido" con capacidad de convencimiento -"Id y predicad a todas las gentes"- para lo que se necesitarían herramientas retóricas, lógicas, las que inspiraron a Ramón Llull su búsqueda de un lenguaje común para convencer a todos los hombres: cristianos, islámicos y judíos. La metáfora de Pentecostés, unas llamas derramándose por la cabeza de los apóstoles, es una adecuada representación de este modelo. (b) Ciertamente la tesis del «pueblo elegido» puede entenderse también como la negación misma del modelo distributivo desde el momento en que surgen las primeras dificultades con los otros pueblos que no se dejan convencer. El mismo Llull nos da una pista tras el fracaso de la argumentación lógica: la obligatoriedad de la cruzada militar ${ }^{8}$. El capitalismo en la práctica, y el comunismo en la teoría con la tesis de la «lucha de clases»- utilizan el modelo atributivo: un grupo humano, caracterizado por la defensa de intereses, ya económicos, ya ideológicos, entran en conflicto con otros grupos por el control de riquezas, rutas comerciales, religiones, etc.

Lo interesante del artículo de Fukuyama es que la victoria del Liberalismo es entendida como un proceso atributivo en el que se supone que el Absolutismo quedo destruido por la Revolución Francesa; el Fascismo desapareció por la fuerza de las armas en la II ${ }^{\mathrm{a}}$ Guerra de las Mundiales; y, ahora, el Comunismo ha sido eliminado en el campo económico dentro de su apartado de la Redistribución de Bienes: el consumo, que ha resuelto de una vez por todas el problema del enfrentamiento de las clases sociales, no sólo en el mundo Occidental sino también en la Unión Soviética y en China. Bajo la hipótesis de que los Fundamentalismos? y los Nacionalismos no tienen la fuerza suficiente para generar contradicciones (los unos apenas si tienen fuerza en Occidente; los otros se paralizan al conseguir sus demandas) la universalización política (democracia) y económica (mercado común) es un hecho. El tiempo que nos aguarda no será ya el de los héroes sino el de los tristes, el de los melancólicos, el de los decadentes. No será el tiempo de las utopías sino el de las técnicas.

(iii) El impacto que causó este artículo, escrito en clave socio-política, exigía la clave filosófica: el marco ontológico y gnoseológico. Fukuyama apela nada menos que a Hegel para corroborarlo descartando otros posibles modelos alternativos de filosofía de la historia como el ciclico (Platón), el escatologico (S. Agustín), el nihilista (Nietzsche), el catastrofista (Spengler)... Para Hegel, dicho sucintamente, la

\footnotetext{
8 "Car s'hi concreten i s'hi precisen els seus projectes d'una croada militar, ara no pas com un simple sistema subsidiari, condicionat a l'eficàcia de la seva Art i a lo major o menor docilitat dels no cristians a les seves raons "necessàries", ans com una empresa que calia dur a terme, alhora, a la Terra Santa, per a recuperar el sant sepulcre, i a Andalusia, per a passar d'aci a la Berberia", comenta Miquel Batllori en "Introducció" a R. LLULL: Obra escogida, ed. Alfaguara, Madrid, 1981, pp. XXXVIII y XL.

9 Tras la «Guerra del Golfo» de los primeros meses del año de 1991, esta hipótesis no es nada gratuita. pues el Fundamentalismo Islámico no surgio como una fuerza capaz de enfrentarse de igual a igual a Occidente. El Presidente del Gobierno Español que consideró el conflicto como regional fue muy criticado por personas e instituciones que, sin embargo, defendian las conclusiones de Fukuyama. Mera ideologia: alli no anidaba el concepto. Supener que ese conflicto era mundial significaba dar beligerancia al Fundamentalismo, como si reemplazase ahora a la URSS.
} 
historia es una sucesión de acontecimientos que ocurren de manera conjunta y están dotados de sentido, el cual es dado a una autoconciencia que alcanza el momento del Saber Absoluto, formalizable, además, en una Lógica. Marx contradijo a Hegel y estos ciento cincuenta años posteriores a Hegel no han sido sino un rodeo para volver a él. ¿Por qué Hegel creyó en el «fin de la historia»? Porque creía en el Derecho. Sabía que el Estado Moderno requería de un sistema jurídico basado en la verdad y que debía evitar, a cualquier precio, el relativismo. Toda alternativa a este modelo significaba cuestionar el mediador de la vida humana: el Estado. Se reintroduciría el escepticismo, el relativismo (Nietzsche), el barbarismo (el catastrofismo), incluso el romanticismo agrícola (Proudhon).

Hegel tenía un concepto limitativo de la historia porque tenía una concepción finitista de la Naturaleza Humana (del Sujeto, de lo Humano), por contraposición a la infinitud de lo divino. Son muchas las concepciones que defienden el carácter limitado del hombre. Es casi una constante desde perspectivas epistemológicas materialistas. Si la mente es algo «dado»-razona Chomsky- ha de poseer sus límites y la humanidad llegará más pronto o más tarde a ese momento: es una cuestión de tiempo ${ }^{10}$. Hawking, en el ámbito de la Física Teórica llegó a titular una conferencia: "¿Está próximo el final de la Física Teórica?"11. No puede extrañarnos que el materialismo histórico haya caído a veces en el monismo ${ }^{12}$ y que pretendiese alcanzar económicamente también el final de la historia, olvidando a su mentor que sabía que, por ahora. sólo se había alcanzado el "final de la pre-historia» y que, a partir de esta autoconciencia. podría lograrse entrar de lleno en la Historia.

(iv) El «final de la historia» no significa el final de los acontecimientos humanos, sino el fin de la evolución del pensamiento humano sobre estos principios. Rebatir la tesis de Fukuyama exigiría demostrar no que el futuro encierra grandes y trascendentales acontecimientos, sino que éstos estarían movidos por una idea sistemática de justicia política y social, alternativa "real" al socialismo fracasado. Ahora bien, todas estas cuestiones requieren un marco adecuado para ser debatidas: la Filosofía de la Historia.

\section{Filosofia}

Definimos rápidamente el concepto de «filosofía» a modo negativo: (a) La filosofía no es una actividad cspontánea de un sujeto pensante, sino una actividad, una construcción ligada a instituciones político-democráticas, a actividades como el teatro, a planteamientos sobre la existencia humana como el amor, etc. (b) La filosofía no es un discurso en el que cabe todo, sino que posee una terminología propia: Ser, Physis, Nomos, Logos, Kosmos, Aletheia... por referirnos al mundo

\footnotetext{
${ }^{10}$ V. gr., CHOMSKI,N.: Reflexiones sobre el lenguaje, ed. Ariel, Barcelona, 1979, cap. 3.

${ }^{11}$ Cfr. en DAVIS,P.: Proyecto cósmico, ed. Pirámide, Madrid, 1989, pp. 28-29.

${ }^{12}$ Monismo: Teoria que supone la unidad ontológica del mundo por lo que el género humano puede hacer suyo la infinitud del Universo.
} 
griego antiguo. (c) La filosofía no pertenece a la experiencia privada de cada individuo, sino que se construye en el diálogo, y en instituciones adecuadas: la Academia de Platón. el Liceo de Aristóteles, la Stoa de Zenón, el Jardín de Epicuro, etc.

A modo positivo diremos que sus componentes son: (A) Epistemología. Gnoseología: Estudio de cómo el sujeto interviene en el conocimiento de lo que es. (B) Ontología: Estudio de la realidad, de lo que es, con independencia del sujeto. (C) Ético-Político: Tratamiento de los Valores, del Deber Ser, de la Praxis, etc.

\section{Historia}

Acerquémonos al concepto de historia. (a) Historia es un término equívoco. Puede referirse a los hechos historicos mismos (res gestae) o bien a los hechos narrados (historia rerum gestarum) ${ }^{13}$. A falta de términos diferentes como el alemán que posee los términos «Geschichte» para los primeros e «Historik» para los segundos ${ }^{14}$ o el inglés, «Histoty» y «Story», respectivamente, usaremos los cómodos recursos de las comillas o de las mayúsculas: historia para referirse a los hechos $\mathrm{e}$ «historia» o Historia, para mencionar los acontecimientos. (La cursiva denota el concepto).

(b) Pero la extensión del término historia es equívoco también por relación a otras disciplinas que se solapan con ella y con quienes mantiene relaciones muy conflictivas: (i) Seguramente la primera de todas ellas es la Tradición. Mientras que la Historia se construye a partir de restos. reliquias. etc., la tradición se inventa. porque antes de ella no persistía esa configuración. El invento de la tradición, es bien cierto, está vinculada a la justificación política: "Como para Richelieu, la historiografía era para el abad de Sain-Denis [Suger] una parte de su arte de gobernar: justificación de sus acciones, clasificación de sus principios y autorizadas interpretaciones para el aprovechamiento de las generaciones futuras (...) la historia no era para él [Suger] simplemente y ni siquiera fundamentalmente, la documentación del hecho histórico, sino más bien la creación de la realidad política. Y no se hallaba más inclinado que sus contemporáneos a dejar que las pruebas objetivas obstaculizaran los vuelos de la imaginación. Para hacer realidad sus propósitos políticos, Suger

\footnotetext{
${ }^{13}$ HEGEL,G.W.F.: Lecciones sobre la Filosofia de la historia Universal, ed. Rev. de Occidente. Madrid, 1974.

${ }^{14}$ Podemos ejemplificarlo con un texto de HEIDEGGER,M.: "La pregunta por la técnica" en Época de Filosofía, Barcelona,año 1, n 1. 1985, p. 19. "Para la cronología de la ciencia histórica, el comienzo de la ciencia moderna de la naturaleza se encuentra en el siglo XVII. En cambio, la técnica de los motores sólo se desartolla en la segunda mitad del siglo XVIII. Sólo que lo más tardio para la comprobación historizante (historish). la técnica modema, es lo históricamente (geschichtlich) más temprano (Frïhere) respecto de la esencia que impera en ella".
} 
recurrió a la poesía y a la fábula"15 (ii) No menos interesante es la relación de la Historia con la Sociología: "La historia ha importado masivamente la técnica estadística, y a menudo ha llegado a convertirse, sobre todo por la vía del marxismo académico, en una sociología diacrónica"16. (iii) Asimismo la Historia y la Etnología han entrado casi en términos de reducción de la una a la otra. Si quisiéramos indicar una diferencia irreductible diríamos que la Etnología se fundamenta en leyendas, en mitos ${ }^{17}$ del grupo humano y social, contadas una y mil veces para reforzar la unidad del grupo, y que convierten lo exterior en lo malo, mientras que la historia, cuyo núcleo es los acontecimientos (históricos) que ponen en cuestión la totalidad del sistema, se dirige hacia el exterior para englobar ese acontecimiento en lo sucedido anteriormente. (iv) A veces la historia se ha identificado con la Cultura y se ha supuesto que el desarrollo del hombre cambia al mismo ritmo que el desarrollo cultural. Pero la historia también es la historia de la invarianza de la figura humana: "Y, sin embargo, el cerebro creador de estos conceptos era idéntico al que, hoy día, se enfrenta a las sutilezas de la matemática y de la física. Es precisamente este progreso tecnológico el que nos permite comprender en la actualidad. la evolución humana"18.

(c) La necesidad de demarcar el concepto de historia comporta que haya distintas teorías, según los criterios que se empleen. La reflexión histórica actual tiene un punto de referencia: el Materialismo Histórico. Cada época piensa contra alguien. Si el siglo XIX pensó contra el ldealismo, el siglo XX piensa contra el Materialismo en su versión economicista (eso sí, argumentando que la economía de mercado ha mostrado ser superior a la centralizada ;Qué bello ejemplo de «la negación de la negación»!).

\section{Filosofía de la Historia}

Una filosofía de la historia se ha de definir por su racionalidad. ¿Cómo se configura esta racionalidad? Ensayemos algunos criterios que la desmarquen de concepciones «míticas», «teológicas», etc.

1.- Se ha de referir a los hechos, a los materiales históricos, a la historia efectiva, a materiales fechados.

15 SIMSON,O.: La catedral gótica. Alianza Editorial, Madrid, 1980, pp. 92-100. "La historia es la tradición que un poder victorioso se otorga a si mismo" escribe JUNGER,E.: El trabajador, ed. Tusquets, Barcelona, 1990, p. 83.

${ }^{16}$ BADIOU,A.: Le nombre et les nombres, ed. Seuil, Paris, 1990, p. 12.

17 "El mito no es ni una mentira ni una confesión: Es un rodeo ... Frente a la alternativa de desvelar el concepto (lo significado por el mito) o de liquidarlo, el mito encuentra una salida distinta que es hacerlo «natural» ... El mito trasforma la historia en naturaleza". BARTHES,R.: Muthen des Alltegs, 1970, p. 112.

${ }^{18}$ WASHBURN.S.L.: "La evolución de la especie humana" en Investigación y Ciencia, Noviembre, 1978 , p. 128. 


\section{2.- Toma como sujeto a la humanidad ${ }^{19}$.}

3.- La Humanidad no puede quedar absorbida en procesos cósmicos sobrehumanos, cósmicos, extraterrestres ${ }^{20}$.

4.- Considera el «cambio histórico» (el paso de un período a otro) causado por uno o varios factores aislables. es decir, racionales, rechazando las leyes englobadoras que todo lo explican ${ }^{21}$.

5.- Vinculada a la defensa de algún modelo de sociedad o de Estado. De ahí el criterio de hallar las filosofías de la historia en los pensadores cercanos a algún hecho crucial $^{22}$ : la batalla de Egospótamos, el saqueo de Roma por Alarico, la Revolución Francesa...

Alcanzamos así la racionalidad histórica, al homo historicus, frente al homo iniciaticus, al homo astrologicus, al homo mythicus, al homo extrasensorial, etc. La historia es la historia del hombre, de sus producciones: Verum est factum, que decía Vico $^{23}$.

\section{El sentido de la historia}

Y, sin embargo,... se repite ad nauseam que el hombre ha perdido, si es que alguna vez lo tuvo, el sentido de la historia, transformándose ya en un ecologista que se inclina hacia la Naturaleza, ya en un consumista que se inclina hacia el Tecnicismo. Hace un par de siglos se enfrentaron dos grandes pensadores que diseñaron el plano sobre el que aún hoy se discute: qué puntos han de reformarse, qué lugares y momentos han de orientar al resto, etc. Uno de ellos, Hegel, describe un proceso racional y consciente en el que grandes y variados sucesos van encajando felizmente: "Tiene que llegar un día en que para comprenderse este rico producto de la Razón activa, que la Historia del mundo nos ofrece ...". El otro, Schopenhauer,

\footnotetext{
19 "Para concluir con prudencia y cautela: o los monstruos tan raros que se citan de algunos pueblos no existen en absoluto: o si existen, no son hombres, y si son hombres, proceden de Adán" escribe $S$. AGUSTÍN en La Ciudad de Dios, Libro XVI, cap. 9 (p. 249 de la edición de la BAC).

${ }^{20} \mathrm{~V}$. gr., que la historia humana y su sufrimiento sea una fatalidad como denunciara ya SARTRE,J.P.: Crítica de la Razón Dialéctica, I. ed. I osada, Buenos Aires, 1970, p. 183.

${ }^{21}$ PRIETO,A.: La historia como arma de la reacción, ed. Akal, 1976, p. 41.

${ }^{22}$ V. gr., para el marco de la antigüedad, CHÂTELET,F.: El nacimiento de la historia,1, ed. Siglo XXI, pp. 233-234. "El ejemplo de la batalla de Egospótamos -aunque Platón no haga nunca alusión precisa a ella- se impone aquí: la cruel derrota sufridas por los atenienses en parte se debió a la indisciplina de los soldados y la falta de autoridad del jefe. Sin embargo, no es debida al azar, y refleja fielmente, dentro del ejército, la anarquia reinante en la democracia ateniense (...) Puesto que la corrupción es necesaria e intema, es necesario que se encuentre en sí misma el principio de su nacimiento". Para el marco de la modemidad, LÖWITH,K.: De Hegel a Nietzsche, ed. Sudamericana, Buenos Aires, 1974, p. 284. "Sólo la Revolución Francesa, mediante la destrucción de la tradición, tuvo sobre la conciencia de los contemporáneos a ella, un efecto historizante, pues a partir de ella se concibió la época, en contraste con todas las que se habian sucedido ahasta entonces", de un modo expresamente histórico-temporal. Por eso tenía el futuro ante los ojos".
}

${ }^{23}$ VICO,J.B.: Ciencia Nueva, ed. Orbis, Barcelona, 1985. 
ridiculiza semejante pretensión: el Mundo es irracional por esencia y fruto de una voluntad ciega. La Revolución de Octubre, siquiera momentáneamente, es un triunfo de las tesis hegelianas y se produce «una vuelta a Hegel» ${ }^{24}$. Poco después, el pesimismo envuelve la creencia racional -que no la fe, eso no nos afectaría- en la historia. Y se justifica razonadamente:

a.- Razones económicas: Tomemos el mercado como metáfora ( 0 quizás como metonimia?). Cada cierto tiempo hay que recoger beneficios a tanto por el riesgo ${ }^{25}$. Es en la concurrencia en el mercado en donde se recibe la determinación ontológica: «SER es ser un VALOR DE CAMBIO» ${ }^{26}$. Las cosas reciben el sentido por su valor de cambio (incluidas las antigüedades) y no por su determinación histórica.

b.- Razones políticas: Es necesario olvidar la Guerra Civil Española, las Guerras Mundiales, la Guerra del Vietnam, etc.

c.- Razones ideológicas: La irrupción de la Vida (Nietszche) y su mundanización; experimentar el cuerpo (ácido, música, etc.) frente al altruismo. Incluso el marxismo pone su granito de arena: el hombre hace la historia, pero bajo circunstancias que no podemos elegir y éstos no son tiempos para la revolución.

d.- Razones existenciales: La amenaza nuclear, la destrucción de la naturaleza paralizan la voluntad de cambio. Hace algunos años se insistía: ¡no hay dialéctica de la naturaleza! Las sociedades son lo diferencial. Hoy lo gris son las sociedades, tan homogéneas, tan semejantes, y se vuelve hacia la naturaleza ${ }^{27}$.

Estas no son sino razones mundanas que están dichas en la conversación cotidiana, en los espectáculos. "Esperando a Godot" es, seguramente, su mejor galardonada obra de arte ${ }^{28}$. Pero también los filósofos han dado razones académicas. El sentido de la historia ha sido impugnado por los teóricos de la reflexión con la, en cierto modo, sorprendente conclusión: lo histórico ha quedado abolido, hay que desprenderse de lo histórico como de un mal sueño. Los historiadores no son más que unos buenos profesionales que ponen fechas ${ }^{29}$. La historia, como punto de

24 El éxito de los cursos de KOJÉVE. 1933-1939, a nuestro juicio, hay que entenderlo en este contexto. Estos cursos están traducidos al castellano en ed. La Pleiade, Buenos Aires, 1972, 1975, 1984.

${ }^{25}$ Cfr., SCHMIDT,A.: Historia y Estructura, ed. Comunicación, Madrid, 1972, p. 15.

${ }^{26}$ Cfr., v. gr., MARTINEZ MARZOA,F.: La filosofía de "El Capital», ed. Taurus, Madrid, 1983. p.103. "... lo que Marx pretende encontrar como la naturaleza del mundo modemo, quizá aún no llevada hasta sus últimas consecuencias en el momento en que Marx escribe, es el carácter de un mundo en el que todo cuanto es es sólo en la medida en que es una (al menos posible) mercancía. En el que el poema sólo es en la medida en que tiene un «valor» en el sentido de la teoría del valor (por lo tanto, cientamente, no en la medida en que es poema)".

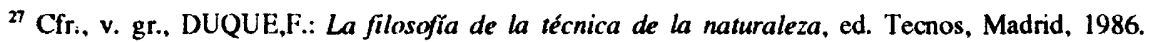
RODRÍGUEZ RIAL,N.: $O$ planeta ferido, ed. Novo Século, Santiago de Compostela, 1991.

${ }^{28}$ El triunfo del sentido, la reconciliación humana, ha quedado reducido al colmo del sinsentido. Debiendo ser dichoso se es infeliz. Nada queda por hacer sino ... esperar a Godot.

29 "De hecho la historia no está ligada al hombre ni a ningún objeto particular. Consiste totalmente en su método, del que la experiencia demuestra que es indispesable para inventariar la integridad de los elementos de una estructura cualquiera, humana o no humana". LÉVI-STRAUSS,Cl.: El pensamiento salvaje, FCE, México, 1972, p. 380. 
referencia desde la que organizar la actividad comprometida de los hombres, es una vana esperanza, y la voluntad de cambiar la vida de los hombres hacia la libertad, hacia la justicia, hacia la solidaridad, mero dogmatismo. En la POST-HISTORIA la técnica y la ciencia se trasmutan en "concepciones del mundo», en «diseño», en "arte», en "estética»". Muchos han sido los dioses de la post-modernidad y, entre nosotros, Vattimo su profeta ${ }^{31}$. Armado conceptualmente con Ideas tomadas de Nietzsche y Heidegger -dicho un poco gruesamente quizá- llega a esta tesis: desde Sócrates hasta nosotros mismos, los hechos históricos no han sido más que errores, y la única manera de salir de esta podredumbre es olvidar a quienes «han olvidado al ser» y comenzar una nueva vida.

\section{El fin de la modernidad}

Modernidad es sinónimo de lluminismo, de Racionalización y, sobre todo, para los defensores de la post-historia, de progreso. El proceso de ilustración se apropia de los orígenes (como principio y como fundamento) de la obra humana. Se plantea así una confrontación entre quienes han corrido en busca de esos fundamentos y quienes cuestionan todos los fundamentos surgidos en nuestra cultura occidental. Ahora bien, el post-moderno está a punto de caer en una aporía. Una de las consecuencias del concepto de progreso es la capacidad de historizar los acontecimientos y, en tanto que cambio, permite la posibilidad educativa (aufklärung). Pero entonces, ¿no será la post-historia el estadio «superior» de la modernidad? Tesis eminentemente historicista. Para evitar la paradoja habrá que suponer que el hombre no sólo «piensa» la historia, sino que experimenta el fin de la historia. Mas, ¿como «res gestae» o como "historia rerum gestarum»? Lo que ha de experimentarse ¿pertenece al ámbito de las cosas o de las ideas? Vattimo apuesta por una salida que nos parece dialéctica, aunque a él no. Ni es la experiencia de la catástrofe nuclear (Geschichte), ni es el modo de tener conciencia de que formemos parte de ese proceso (historik). Lo que se disuelve es la Idea de una historia como proceso unitario, a la vez que se instauran las condiciones efectivas de su experiencia: Técnica-Informatización, que le da una especie de inmovilidad histórica. Gehlen ${ }^{32}$ lo ha radicalizado: el progreso se convierte en rutina. Ciencia y Técnica y Sociedad se han volcado en la supervivencia del sistema. La historia se ha roto en mil pedazos, en multitud de historias. Las gentes mismas viven sus historias. Hasta el «duro» adulterio se ha convertido en el "suave» vivir una historia con $x$ o $y$. La experiencia del fin de la historia se ejercería, por consiguiente, a través de los mecanismos de comunicación que tienden a uniformar la contemporaneidad. Mantener una posición no apocalíptica de la post-modernidad se habrá de vincular a los modelos positivos

\footnotetext{
${ }^{30}$ Cfr., v. gr., ÁFRICA.C.: "Historia" en ¿Qué es el postmodernismo?, Universidad de de Alicante, 1989. pp. 63-79.

31 VATTIMO,G.: El fin de la modernidad, ed. Gedisa, Barcelona, 1987, pp. 9-20.

${ }^{32}$ GEHLEN,A.: Antropología, ed. Sigueme, Salamanca, 1982.
} 
del arte, de la retórica, del saber cientifico. de la ópera, etc ${ }^{33}$.

\section{Del optimismo de la historia}

Si, como dice Ferrater ${ }^{24}$. los estoicos y epicúreos intentaron mantenerse en pie, los poderosos colocarse sobre la realidad y los cristianos ponerse al frente de la realidad para salir de aquella crisis en que se sumio la Sociedad Antigua, los mundos del trabajo y de la intelectualidad en el siglo XIX también quisieron ponerse al frente de la realidad y decidieron que su acción, su praxis, podría cambiar la injusticia, la explotación y las calamidades. A falta de tradición, se apoyaron en la ciencia y, a falta de experiencia, hablaron de la bondad y de la inocencia de los humildes. Pero los presupuestos venían conformándose desde la Reforma, desde el Descubrimiento de América, desde la Idea cartesiana de Sujeto. El «yo», el «sujeto», había quedado oculto por estructuras familiares, tribales y sociales. Recordemos a los muy conocidos «canacos» de Nueva Guinea, estudiados por Leenhardt ${ }^{35}$. El Do Kamo «a», ignora su cuerpo, mero soporte, y se perfila como individuo por sus relaciones con los otros: «a» y su padre; «a» y su madre; «a» y su tío materno; etc. O a los japoneses, cuya lengua carece de pronombres personales fijos: los pronombres son relacionales. Sin duda el «sujeto» ${ }^{36}$ es el punto de arranque de la modemidad. Un sujeto que no puede quedar deslindado de sus acciones. Hasta Descartes y Kant, la Razón había quedado fuera de un «sujeto» que pertenece al mundo, sometido a la Razón y que, como la luz, se impone desde fuera. "El sol no traspasará sus límites. Si no las Erinias, guardianas de la justicia sabrán descubrirlo" había escrito Heráclito ${ }^{37}$. A partir de Descartes, la Razón se recobra como sujeto sustentador de la verdad hasta el punto de establecerse como una regla general que "las cosas que concebimos muy clara y distintamente son todas verdaderas ${ }^{\text {"38 }}$.

Es el genio de Kant quien despliega la Idea de un Sujeto-Razón que impone su ley al Mundo. La colonización americana, la marina de guerra mercante, la ciencia newtoniana... demasiadas cosas para seguir aceptando la doctrina agustiniana que

\footnotetext{
${ }^{33}$ Bunge ha tenido que decir lo evidente cono novedad: "No comemos información ni lo calzamos, no la bebemos, ni nos calentamos, ni nos lavamos con ella, ...la economia siempre tendrá sus sectores de extracción, agropecuario e industrial. por más que éstos sean informatizados".

${ }^{34}$ FERRATLR MORA.J.: Las crisis humanas, Alianza Editorial, Madrid, 1983. p. 59.

${ }^{35}$ L.EENHARDT,M.: Do Kamo (la persona y el mito en el mundo melanesio). EUDEBA. Buenos Aires, 1961.

${ }^{36}$ La historia del concepto asujetom nos llevaría demasiado lejos. Habria que remontarse a los brujos siberanos, según la difundida tesis de DCDDS,E.R.: Los griegos y lo irracional, Alianza Editorial. Madrid. 1980, pp. 137 y ss. que, tras injerir algunas drogas asalian» de su cuerpo. Esta experiencia seria tematizada por Platón, que defiende un alma inmortal y simple en el Fedón. Los estoicos forjan el concepto de epersonaw, y el Derecho Romano defiende la propiedad individual, notas que sistematiza $S$. Agustín, universalizadas y laicizadas en la Declaración de los Derechos Hunıanos.

${ }^{37}$ HERÁCLITO, $\$ 94$ de la edición Diels-Kranz.

${ }^{38}$ DESCARTES: El discurso del método, parte IV.
} 
operaba con una criatura perezosa. mísera y en peregrinaje por la tierra, viviendo un drama que Dios había pensado y que ella representaba inconscientemente. A partir de Kant, el hombre, sujeto y fundador de sentido, relega como un arcaísmo o prefiguración el pensamiento anterior que expresaba al hombre viviendo en un valle de lágrimas. Y si hasta el siglo XVIII el hombre "crea» las teorías científicas, culminación de aquel proceso de suposición de hipótesis «imaginarias» (la teoría de los epiciclos, la teoría copernicana, en cuyo prólogo el editor Osiander insiste en su calidad de hipótesis. hipótesis-postulado, situadas fuera del dominio de lo verdadero o falso), en el sigo XIX el hombre vulgar se autoconsiderará "creador» del mismísimo mundo social, político y económico. "El hombre -había dicho ya Vicono conoce más que lo que él hace" ${ }^{139}$. Y será en el taller filosófico de Hegel donde se gesta la Idea que aún hoy nos conmueve: incluso la Naturaleza es un resultado de la acción, de la Potencia Activa del hombre: la antinomia libertad/necesidad adquiere todo su valor y dimensión.

Con Hegel cristaliza el concepto (científico) y la Idea (filosófica) de HISTORIA. A partir de él, tres vías destacan por sobre las demás: (A) La Filosofía de la Praxis: Marx-Lukács-Sartre. (B) El Historicismo: de Dilthey a Gadamer, pasando por la Escuela histórica alemana: Niebuhr y Ranke. (C) La Suprahistoria: de Nietzsche a Heidegger. Sólo cuando se agotan estas vías, aparece el fantasma del «fin de la historia».

(A) FILOSOFÍA DE LA PRAXIS: Se incluye en el ámbito de la filosofía trascendental, de la búsqueda de las condiciones que hacen posible un cierto estado de cosas. Hegel había ordenado todos los hechos de tal forma que su totalidad tuviese un sentido. Éste sería el significado de la modernidad: todo tiene sentido, nada queda al margen, todos los hechos confluyen hacia la razón ${ }^{40}$. Pero entonces el hecho, el acontecimiento singular pierde su sentido histórico. Si éste es racional, los acontecimientos son efímeros. ¿Qué le queda al hombre? ¿Cuál es su lugar en la historia? El concepto que hay que pensar es el de tiempo histórico. A ello se aplican los jóvenes hegelianos. y también Kierkegaard, para dar un sentido al hombre de carne y hueso, que trabaja, que come ${ }^{41}$. Si Hegel había considerado como portadores del desarrollo histórico al Estado y a su Conciencia (el espíritu nacional), Marx pensará el hombre como un ser práctico, como praxis, que es el resultado de la crítica al Geist (Espíritu) hegeliano. (a) En un primer momento, como crítica implacable a todas las instituciones existentes (Espíritu Absoluto de Hegel) (b) En un segundo momento, como fuerza material (reestructuración del Espíriru Objetivo) (c) En un tercer momento, como alienación (Espíritu Subjetivo). Marx da la vuelta (umstülpung) a Hegel que, en términos lógicos significa invertir la relación sujetopredicado. El Espíritu (la Razón) no puede ser sujeto porque no es fuente de actividad, sino predicado, resultado de la acción de sujetos activos y reales. La gran Idea de Hegel -que el hombre es su acción, que el hombre objetiva sus productos y

\footnotetext{
${ }^{39}$ VICO,J.B.: Ciencia Nueva, I, op. cit., pp. 141 y 149, v. gr.

${ }^{40}$ RUBERT DE VENTÓS,X.: De la modernidad, ed. Península, Barcelona, 1980, passim.

${ }^{41}$ FEURBACH escribe: "Der Mensch ist was er isst" ("El hombre es lo que come").
} 
se separan de él- es entendida como categoría ontológica, pero Marx la transforma en categoría social: la acción, la praxis no pertenece ya a la naturaleza humana, sino a determinados conjuntos de instituciones y prácticas. En el capitalismo, v. gr., la objetivación es alienación, consecuencia de las condiciones de trabajo. El producto de su trabajo se le opone como algo extraño; su actividad productiva ya no es suya sino del «Otro", por lo que queda enfrentado al producto y a los otros hombres. ¿Cómo superar su alienación y recuperar sus productos? No falta sino un pequeño paso para el requerimiento de una Praxis Revolucionaria y lograr una sociedad humana en la que el hombre se reapropie de su esencia, de su vida específica. El hombre, ahora, se atreve a dirigir su HISTORIA. El ¡Sapere aude! kantiano (¿Atrévete a pensar por ti mismo!) queda transformado en: ¡Atrévete a construir racionalmente tu propia historia! Con la Revolución Francesa, la Revolución Industrial, el desarrollo de las ciencias, los hombres se disponen a cambiar las condiciones de vida, y los conceptos filosóficos de reflexión, formación, autoconsciencia se sustituyen por los socio-históricos de producción y trabajo ${ }^{42}$. La Revolución de Octubre validó la teoría. Pero un hecho tan insólito requería no sólo de una explicación, sino de una «legitimación». Lo que se produjo «aparentemente» fue que el pueblo trabajador. sus vanguardias, tomaba el poder. Y sólo si se incorporaba a una tradición historica podría negarse que fuese un puro acto de violencia.

Lukács echa las bases de su legitimación. (i) La capacidad de hacerse «sujeto» de la historia por parte de grupos sociales cuya morfología había sido perfilada por Marx: el proletariado ${ }^{43}$. (ii) La Revolución de Octubre no es una rebelión espontánea, sino que comporta una racionalidad y una justificación. Lukács reflexiona la experiencia de los espartaquistas, de los consejos obreros húngaros, de los soviets rusos que en diez. veinte años habían alcanzado una organización enorme y con un resultado sorprendente, desde economatos hasta teatros para el ocio, y cuyo buque insignia fue el partido socialdemócrata alemán. Estamos en el apogeo del optimismo de la historia.

(B) EL HISTORICISMO: Si la filosofía de la Praxis está vinculada a la Ilustración (Berlín), el Historicismo lo está al Romanticismo (Weimar), y, ambos, por mediación del Idealismo Alemán. Si la Ilustración estuvo sostenida por la burguesía y cristaliza en círculos donde participan con entusiasmo mentalidades cosmopolitas, el Romanticismo supuso la voz de los nacionalismos, que -al disolverse las instituciones esencialmente jerarquizadas del Antiguo Régimen por la Revolución Francesa y ser reemplazadas por instituciones bajo la regla de la igualdad civil-, se instalaron como evidentes: todos los hombres son iguales, en tanto que "enfants de la patrie».

El Romanticismo se caracteriza por un interés profundo en la vida interior del

\footnotetext{
${ }^{42}$ Cfr., v. gr. HABERMAS.J: Conocimiento e interés, ed. Taurus, Madrid, 1982.

${ }^{43}$ PROLETARIAIX): "Sujeto social que se adueña de su propio destino históico de una forma concreta, es decir, organizada y consciente, de adueñarse de la totalidad de la historia, y aimila como su propio productor".
} 
hombre, por privilegiar el sentido frente a la razón, por su amor cuasi-místico a la naturaleza, por una fascinación de lo antiguo o por un deseo de fusión cósmica con lo infinito de la naturaleza (un monismo orgánico). $Y$, sobre todo, por ser un movimiento particularista alemán frente a la universalización ilustrada. El sujeto romántico trata al mundo como motivo u ocasión de su productividad. Por relación a la Ilustración, que acepta una norma exterior y superior a él (el siglo XVIII no es ateo, sino deísta), el romántico, extrapolando a Kant, cree en la capacidad creadora del espíritu humano, no tanto como productividad (ligado al trabajo), sino como genialidad (ligado al arte). De este doble movimiento, la creatividad del hombre -del héroe, del genio-, y de la necesidad de legitimización de la sociedad moderna que ha arrumbado a la sociedad tradicional, surge la necesidad de construir una FILOSOFÍA DE LA HISTORIA, consumada en Hegel. Pero esta historia tuvo que vérselas con el materialismo y el positivismo de las revoluciones científica y evolucionista.

Es Droysen quien ofrece un marco adecuado para esta reflexión. Si el a priori «espacio» explicita las condiciones de posibilidad de la Naturaleza, el a priori «tiempo» explicitará las condiciones de posibilidad de la Historia. Se trata de deducir las categorías del «tiempo" (irreversible por contraposición al tiempo reversible de la física newtoniana). Si la deducción de las categorías kantianas se hizo por mediación de los «juicios» según la lógica (aristotélica), ahora se hará por medio de la comprensión (la Einfülung herderiana). El historicismo retoma algunos desideratum de Diderot y de Hume hacia un Historicismo Absoluto: «Nadie puede comprender la ciencia natural a no ser que comprenda la historia». Las dos grandes figuras del historicismo fueron Ranke como historiador, y Dilthey como filósofo de la historia, que lucha por la autonomía de las ciencias del Espíritu, basadas en la comprensión (vershehen), frente a las ciencias de la Naturaleza, basadas en la explicación (erkennen). Más tarde Max Weber desarrolla la historia como un proceso de interpretación. La característica esencial es comprender la realidad social en su singularidad e individualidad. Esos hechos o actos singulares están guiados por intenciones, por motivos. Por lo tanto, la integración de las aporías se realiza a escala humana y no en alguna suerte de plan de la naturaleza como pretendió Kant. La hermeneútica será la consecuencia de este planteamiento: revivir, reconstruir, en un acto de comprensión, las vivencias históricas.

Si Dilthey recurrió a la psicología. Windelband y Rickert ${ }^{44}$ tratarán la cuestión desde una perspectiva metodológica. Se distingue entre ciencias nomotéticas. (determinismo causal, abstracciones. generalización) y ciencias ideográficas (peculiaridades, singularidad). clasificación que reemplaza a la distinción ontológica: Naturaleza/Espíritu. Ambos impugnan la tesis epistemológica aristotélica: "No hay ciencia más que de lo universal"45. Si la ciencia es de lo universal, la historia -que se ocupa de lo singular- no es ciencia. Pero, contraargumentan, como la historia es una ciencia. entonces, por modus tollens. la ciencia no lo es de lo universal, y por

\footnotetext{
${ }^{44}$ RICKERT,Il.: Ciencia cultural y cie'ncia natural, ed. Espasa-Calpe. Madrid, 1946.

${ }^{45}$ ARISTÓTHLLS: Poética. 1451 h.
} 
contraposición, ha de serlo de lo singular. En conclusión: hay ciencia de lo individual. Mas no se hablará ahora de leyes, sino de figuras, de formas, que el historiador ha de vivificar por medio de la Intuición, corolario de la einfülung.

Bien es cierto que el historicismo contiene un germen de disolución: el relativismo, porque -como se ha puesto muchas veces de manifiesto ${ }^{46}$ - es contradictorio. Si el fenómeno histórico puede un día llegar a desaparecer entonces el historicismo será válido absolutamente. Ahora bien, si toma un valor absoluto, la tesis del historicismo no es historicista. Y si no es historicista y dice que puede llegar a desaparecer, entonces dice iexactamente! que es historicista. La paradoja es bien clara.

(C) LA SUPRAHISTORIA: Pero el Romanticismo no sólo acercó los temas medievales; también exploró la tradición esotérica, perdida por entre oficios populares ${ }^{47}$, y la quiso reencontrar en los libros orientales, los Veda, las Upanisad, el Zen, etc. Algunos quisieron ver en estas corrientes la Vida, por oposición a la Historia, a los metarrelatos. Se requería una enérgica transformación en el punto de partida, en el origen de nuestra cultura. Schopenhauer supo encaminar al noumeno kantiano, hacia lo infinito, hacia lo irracional, por vías distintas a las seguidas por el logos, por la Razón, y eligió la Voluntad. Si bajo el criterio de la representación el hombre está sometido a las leyes naturales, bajo el criterio de la voluntad el hombre es libre. La Voluntad será una de tantas estructuras de la naturaleza que mueven al mundo (junto con la Gravitación, v. gr.), pero todas ellas dirigidas por la voluntad de vivir. El noumeno sería así alcanzable, no por el método científico (vinculado a la industria, a la tecnología. muy cerca del proletariado: armas y trabajo), sino por el método artístico. La voluntad se mueve por un deseo inagotable. Su falta de consumación nos convierte en un mundo de dolor, de sufrimiento, de lágrimas, que sólo puede purificarse a través de la obra de arte, y, por encima de todas ellas, la música ${ }^{48}$. El despliegue de objetivación hegeliano-marxista y la filosofía de la praxis se reemplaza por el recorrido del sufrimiento, del dolor, de las miserias, de las necesidades y, en última instancia, de la muerte. La Historia queda relegada a la reproducción de estas miserias. La historia ya no está sometida a la acción humana autoconsciente y racional. sino a la voluntad ciega, al deseo y plantea un nuevo camino para objetivar la voluntad: el arte.

Nietzsche, su continuador, quiere inventar un nuevo lenguaje y negará tanto las tesis dialécticas de la filosofía de la praxis como las positivistas de los historicistas, para reivindicar el mundo de la Vida. El hombre alcanza el placer de existir

${ }^{46}$ V. gr. ARON,R.: Las etapas del pensamiento sociológico, I, ed. Siglo Veinte, Buenos Aires, 1983, pp. 47-55. POPPER,K.: La sociedad abierta y sus enemigos, ed. Paidós, Barcelona, 1980, p. 419. GADAMER,H.G.: Verdad y método, ed. Sígueme, Salamanca, 1977, pp. 630-631.

${ }^{47}$ Pueden leerse con provecho algunos libros que ponen de manifiesto cómo estas corrientes esotéricas salian a la luz arropados con lenguajes de la tradición exotérica, el delicioso libro de GUINZBURG,G.C.: El queso y los gusanos, ed. Muchnik. Barcelona, 1981, o REGUERA,I.: Objeto de melancolia (Jacob Böhme), ed. Pluma Rota, Madrid, 1985.

${ }^{48}$ Deben leerse las bellas páginas de Vidal PEÑA: "Schopenhauer y la música" en El Basilisco, nº 4, $I^{2}$ época, pp. 29-34. 
solamente en dos estados: en el sueño y en la embriaguez. (a) El sueño.- Ahí el hombre es el sumo artista creando nuevos mundos. La luz que penetra los sueños y los hace bellos es la verdad. No hay que rebasar los límites del sueño, sólo la apariencia soñada es verdadera. Apolo será el dios de las representaciones oníricas. (b) La embriaguez.- Dionisos. por contra, representa el desbordamiento de esos límites. Las cosas quedan difuminadas haciéndose presente un todo infinito. Lo dionisíaco reconcilia al hombre con la naturaleza misma y hace que él, humano, se sienta una divinidad. Occidente ha reforzado la vía de Apolo, la «racional», la del logos, y ha infravalorado a Dionisos. Eso dice Nietzsche. El hombre se ha perdido y ha de volver a aquella encrucijada en la que se desorientó. Ha de enfrentarse a la Historia desde la Vida. y el Mito será la herramienta adecuada: el mito que habla de montañas, gigantes, príncipes encantados, conceptos todos que están por encima de la «escala humana». Al eliminar la escala de la «Razón», de la «Gramática», de la «Ciencia», y sustituirla por la escala del «Mito», también se elimina la Historia que, fecundada ahora por el Mito, se trasmuta en SUPRAHISTORIA. Los conceptos supra-históricos serán aquéllos que dominan siempre cualquier etapa de la historia: como la muerte, como el sexo, como la tribu... Si en Schopenhauer la suprahistoria era gris porque sus conceptos eran muy genéricos, en Nietzsche se concretan más en la experiencia artística: de ahí sus esperanzas -frustradas- en Wagner, que quiso llevar la experiencia total del origen a la ópera. $\mathrm{Ni}$ en Wagner ni en Nietzsche hay trama histórica: toda la historia se ofrece en un momento único en el que se ha de experimentar el origen. De tal modo que Wagner pretenderá reconstruir la totalidad histórica en un par de horas sobre el escenario.

\section{Pesimismo histórico}

Hasta la Primera Guerra Mundial los hombres europeos, mayoritariamente, creyeron en la acción y en la emancipación del hombre. Pero la historia (res gestae) sigue su marcha. Ya se habían dado serios avisos al optimismo. Las crisis de 1830 , 1848,1870 van echando por tierra las esperanzas puestas en la Revolución (Francesa) tanto por parte de la burguesía ${ }^{49}$ como del pueblo. "La Revolución Francesa -decía Lord Acton- enseño al pueblo a considerar sus deseos y necesidades como criterio supremo de legalidad". Esc pucblo. las masas, empiezan a cristalizar ${ }^{50}$. a tomar forma, con la creación de los partidos socialdemócratas en el decenio de los ochenta. La falta de estructura intelectual adecuada para responder hará que ese conglomerado de fuerzas que va desde la burguesía liberal a la burocracia imperial den una respuesta violenta ${ }^{51}$. La ciudad. foco de nivelación social y cultural, es atacada por los artistas, los filósofos, los teólogos. Ataque que se tematiza como «decadencia de

\footnotetext{
${ }^{49}$ Cfr., v. gr.. BERMAN.M.: Todo lo sólido se desvanece en el aire, ed. Siglo XXI. Madrid, 1988. También SCHORSKE.,CE.: Viena fin-de-Siècle, ed. G. Gili, 1981.

${ }^{50}$ Para su concepto, CANETTIF.L.: Masa y poder, ed. Muchnik, Barcelona, 1977.

${ }^{51}$ Cfr. MAYER,A.J.: La persistencia del Antiguo Régimen, Alianza Ed., Madrid, 1984.
} 
Europa» justo cuando, paradójicamente. Europa lleva a cabo la conquista del resto del mundo. En vez de analizar la democracia, se refugian en bohemias, con sus poetas malditos, sus estetas decadentes. sus dandis y su odio a la muchedumbre vulgar. Ortega y Gasset lo vio plenamente con agudeza crítica: "El sentido de aquellos derechos no era otro que sacar las almas humanas de su interna servidumbre y proclamar dentro de ellas una cierta conciencia de señorío y dignidad ino era esto lo que se quería? ¿Que èl hombre medio se sintiese amo, dueño, señor de sí mismo y de su vida? Ya está logrado. ¿Por qué se quejan los liberales, los demócratas, los progresistas de hace treinta años? ¿O es que como los niños quieren una cosa pero no sus consecuencias? (...) La subvención de las masas significa un fabuloso aumento de vitalidad y posibilidades; todo lo contrario, pues, de lo que oímos tan a menudo sobre la decadencia de Europa. Frase confusa y tosca, donde no se sabe bien de qué se habla, si de los Estados europeos, de la cultura europea..., de la vitalidad europea" 52 . Este «Espíritu Subjetivo» hubo de preparar una de las aberraciones más logradas de este pesimismo latente: el fervor para alistarse en los ejércitos de un número de estudiantes y jóvenes cultos de toda Europa que, como en un gran ritual de purificación apocalíptico, preludio de un Renacimiento Total, quedaron destrozados en las trincheras dirigidos por oficiales con mentalidad feudal y armamento supermoderno $0^{53}$. Los jóvenes que no murieron quedaron horrorizados por la experiencia. La Revolución triunfa en Rusia y se inicia la experiencia comunista que mantendría aún la esperanza de la Filosofía de la Praxis. Pero los modelos optimistas sobre la historia y la emancipación humana se alejaban de Europa, y el nervio histórico desaparece poco a poco: África, Oceanía serán los paraísos para la Etnología. La sociedad soviética, para la Sociología. Europa se recrea en la Estética. "Cualquier tonto puede hacer historia; pero hace falta un genio para escribirla" redondea Oscar Wilde.

El pesimismo histórico tiene un contexto filosófico: la Idea de Sujeto que plantea cuestiones decisivas en términos tanto teóricos como existenciales. ¿Qué ocurre si el hombre llega tarde a la toma de decisiones? ¿Qué ocurre si interviene incorrectamente? Si el sujeto hace su historia y el hombre es consciente de su responsabilidad, de la situación que vive respecto de la siguiente -la historia ya no es un proceso natural, ¿podrá ser castigado, y cómo, si se desvía del camino histórico? Se abre la puerta así a los «procesos» contra los rebeldes, los desobedientes de la marcha histórica. La historia se convierte en justificación de la persecución y de la muerte.

La historia, desde Marx al menos, se mueve en una gran dicotomía: (a) $O$ el motor de la historia es la lucha de clases (Manifiesto de 1848). (b) O lo es la serie de contradicciones entre las fucrzas y las relaciones de producción (Contribución de 1859). De otra manera: $O$ bien se ha de estar en continua alerta para evitar el retorno de la barbarie (Rosa Luxemburgo y los espartaquistas) o bien es el despliegue de las fuerzas productivas el garante del tránsito evolutivo de la sociedad burguesa al

\footnotetext{
${ }^{32}$ ORTEGA y (jASSET,J.: La rebelión de las masas, ed. Espasa Calpe, Madrid, 1969, pp. 44 y 48.

${ }^{33}$ STROMBERG,R.: Historia intelectual europea desde 1789, ed. Debate, Madrid, 1990, dedica algunas paginas impresionantes de estos mumentos.
} 
socialismo (posición defendida por Kautsky y la $\mathrm{II}^{\mathrm{a}}$ Internacional). Esta polémica no sólo tiene lugar en el plano de la política, sino en el plano de la investigación histórica. Mientras que, por ejemplo, Brenner defiende la posición (a) para explicar el paso del «feudalismo» al «capitalismo», Guy Bois defiende la posición (b) ${ }^{54}$. Esta dicotomía está en el corazón mismo del gran debate entre el Existencialismo y el Estructuralismo ${ }^{55}$.

Así las cosas, la Historia, en su acepción como Materialismo Histórico se desmorona. M. Cruz ${ }^{56}$ utiliza un criterio genérico para clasificar las críticas al, en general, «historicismo»: desde el interior mismo del marxismo; desde el exterior. Sin negar su capacidad de discriminación epistemológica, al modo de las clasificaciones lógico-internalista/sociológico-externalista de la ciencia, nos parece que es necesario incluir un criterio gnoseológico, operatorio, que nace de la consideración científica de la historia. Ésta ¿se ocupa de leyes generales o de la explicación de actos singulares, irrepetibles? Pero la «acción» tiene que ver con el individuo y éste con el total del que forma parte. Y la «estructura» tiene que ver con la totalidad y ésta, a la inversa, con lo individual de que se compone. Las relaciones Economicismo/Voluntarismo, cuyo contexto es socio-político, se presentan como Estructura/Sujeto en los campos ontológico y epistemológico, y como Totalidad/Individuo en los terrenos lógico y gnoseológico. Y, en el contexto material que aquí tratamos, la Historia tiene que ver con la orientación de una historia total, como la de Annales o de una historia evencial, de acontecimientos, de sucesos, como la clásica de Ranke.

Utilizaremos el criterio de las totalidades combinatorias y porfirianas. En las primeras, las notas intensionales, unidas de modo disyuntivo, tienen lugar extensionalmente a través de otras que están negadas y que necesariamente tienen que aparecer. Valga como ejemplo «los derechos jurídicos» (j) de determinado grupo humano. Pueden aparecer en un contexto donde se nieguen los derechos de propiedad (jv $\neg$ p), o donde se nieguen los derechos de las mujeres (jv $\neg \mathrm{m})$, o de la naturaleza (jv $\neg n)$, etc. La lucha de clases se da fundamentalmente en contextos combinatorios, sobre totalidades atributivas. Pero en el «economicismo» estas propiedades se entienden más bien, y por contra. como totalidades porfirianas. Así, el derecho a tener un juicio justo se entenderá como absoluto, independiente de los otros derechos, el de propiedad, v. gr. El derecho (Universal) se distribuye por cada uno de los individuos de la clase. recogidos por ejemplo en la Constitución ${ }^{57}$. Vamos a ejemplificar estos conceptos en dos pensadores que se han ocupado de la historia: Popper y Lévi-Strauss.

(I) Críticas de tipo combinatorio: Popper. Entre las dos grandes guerras existe conciencia de vivir una época crucial. Se escriben libros cuyos títulos son bien elocuentes: Crítica de la época (1913); La decadencia de la tierra por el espiritu

\footnotetext{
${ }^{\$ 4}$ Cfr. ASTON.T.H \& PHILPIN.C.H.E.: El debate Brenner, ed. Critica, Barcelona, 1988.

ss ANDERSON.P.: Tras las huellas del materialismo histórico, ed. Siglo XXI, Madrid, 1986.

${ }^{56}$ CRUZ,M.: El historicismo. ed. Montesinos, Barcelona, 1981.

${ }^{57}$ Esta distinción puede localizarse en LLSNIEWSKI,S.: "Sobre los fundamentos de las matemáticas" en Teorema, vol.XIII/1-2, 1983, pp. 21-91.
} 
(1916); La crisis de la cultura europea (1917); La decadencia de Occidente (1918); Los últimos días de la humanidad (1922)... Sus autores: W. Rathenau, Th. Lessing, R. Pannwitz, O. Spengler, K. Kraus. Frente a ese tono entre apocalíptico y sentimental, Popper ofrece una respuesta en clave científica y epistemológica. Ante las negaciones fervorosas de la cultura occidental o de sus violentos defensores. se deja oír una voz pretendidamente mesurada que propone soluciones parciales, de ingeniería política, ante los discursos globales y totalizantes del todo o nada. Popper ataca lo que él llama historicismo, aun cuando no se corresponde con ninguna teoría concreta, y que se caracteriza por dos notas: (a) existen «leyes» de la historia. (b) Por tanto se puede «predecir» el destino del hombre. Su argumentación tiene dos partes: Una formal y lógica ${ }^{58}$ y otra material donde muestra la persistente y perniciosa influencia del historicismo sobre la filosofía de la sociedad, ilustrándolo por medio de pensadores «historicistas»: Platón-Hegel-Marx ${ }^{59}$.

La refutación del historicismo se construye como un silogismo. Premisas: $(\alpha) \mathrm{El}$ curso de la historia humana está fuertemente influido por el crecimiento de los conocimientos humanos: $(\beta)$ No podemos predecir (por métodos racionales o científicos) el crecimiento de nuestros conocimientos en el futuro. Conclusión: $(\gamma)$ No podemos predecir el curso futuro de la historia humana. Corolarios: $(\delta) \mathrm{Se}$ ha de rechazar la historia teórica. ( $(\varepsilon)$ La historia está mal concebida y cae por su base. Popper concluye su diagnóstico afirmando categóricamente que "la historia no tiene significado", pues el reino de los hechos es infinitamente rico: arte, lenguaje, alimentación, enfermedades, etc. Sin embargo, la Historia de la Humanidad se sigue definiendo como «historia del poder político».

¿Qué es la historia, entonces, para Popper? El concepto de historia es una necesidad de su planteamiento ontológico y epistemológico. Popper distingue tres Mundos ontológicos: El Mundo I corresponde al mundo físico, biológico. El Mundo 2, al mundo de la experiencia o pensamiento en sentido subjetivo. Y el Mundo 3, al pensamiento objetivo. "Sugiero la posibilidad de aceptar la realidad o (...) la autonomía del tercer mundo y, a la vez, admitir que éste se constituye como producto de la actividad humana (...) El tercer mundo es un producto del hombre, del mismo modo que la miel es producida por las abejas o las telas de araña por las arañas" ${ }^{160}$. Si $\mathrm{M}_{3}$ es un producto del hombre como sujeto $\mathrm{M}_{2}$, entonces ha de tener una historia. que es el mismo proceso mediante el cual se van acumulando los distintos saberes. bajo el criterio epistemológico de la falsación. Su concepción de la historia es, pues. evolucionista. Lo que el hombre segrega es hipótesis-conjeturas. Aquellas que son equivocadas, erróneas, pueden falsarse y rechazarse. La escala de la falsación es individual $\mathrm{y}$, por consiguiente. las hipótesis entran en competencia por medio de individuos particularizados, con sus problemas, sus intereses, etc. La crítica de Popper posee una doble dimensión: (a) En el plano histórico, los individuos. verdaderos átomos sociales, entran en relaciones a través de instituciones. Se

\footnotetext{
${ }^{38}$ En POPPLR.K.: Miseria del historicismo. Alianza Editorial. Madrid, 1973.

${ }^{59}$ POPPLR.K.: La sociedad ahierka y sus enemigos, op. cit.

${ }^{60}$ POPPER,K.: Conocimiento objetivo, ed. Tecnos, Madrid, 1982, p. 152.
} 
reemplaza así la lucha de clases por la competencia entre individuos: "La ciencia, y más especialmente el progreso científico, son los resultados no de esfuerzos aislados [la tesis difusionista, v. gr.]. sino de la libre competencia del pensamiento" ${ }^{61}$. (b) Mas lo que entra en competencia. realmente, son sus hipótesis, igualmente a través de instituciones. Más tarde. las interpretaciones históricas entran también en competencia: "Es posible, por ejemplo, interpretar la «historia» como la historia de la lucha de clases, o la lucha de las razas por la supremacía, o la historia de las ideas religiosas ... Todos estos puntos son puntos de vista más o menos interesantes y, como tales, perfectamente admisibles. Pero los historicistas no los presentan como tales; no ven que hay necesariamente una pluralidad de interpretaciones que tienen básicamente la misma medida de sugestión y de arbitrariedad..." ${ }^{62}$.

Ahora bien, sobre esta acumulación, esta colección de hipótesis -que, por cierto, abre el camino al «anything goes» de su discípulo Feyerabend, «todo vale»-, se ha de construir una clase distributiva, si no se quiere caer en un anarquismo incontrolado. El marco adecuado es, para Popper, la democracia sin restricciones en la que caben todas las hipótesis; y el pacifismo, para que las falsaciones se realicen sin violencia. Sin embargo, y paradójicamente, en el ejercicio mismo de estos universales distributivos, y bajo el pretexto de que hay mayor facilidad para la destitución del gobierno -la falsabilidad política-, defiende la democracia bipartidista, por la que se cuela de rondón otra vez la lucha de dos partidos que, por muy atenuada que se dé en Inglaterra, es la proyección misma de la lucha de clases que se ha intentado conjurar a lo largo de toda la obra popperiana.

(II) Críticas de tipo Porfiriano: Lévi-Strauss. Se enfrenta, por mediación de su polémica con Sartre. a la Razón Dialéctica. ese método que pretende que "nada humano (y aun vivo) le es ajeno"63. Pero si el hombre se define por la Dialéctica y la Dialéctica por la historia, ¿qué ocurre con los pueblos sin historia? No se podrían estudiar porque no son dialécticos y, en consecuencia, no serían humanos, no pertenecerían a la Historia, sino a la Naturaleza. Sartre, a ojos de Lévi-Strauss, sería un eurocéntrico. Pero, además, la antropología sartreana está construida sobre el supuesto de que los protagonistas captan. desde el sentido local de sus acciones, el sentido global de la sociedad a que pertenecen y, sin embargo, desde las prácticas constituyentes no se puede conseguir lo definitivamente constituido. La conciencia del sentido -sostendrá Lévi-Strauss- no es sino actos fallidos (Freud) que han tenido éxito socialmente y es vano indagar el «verdadero» sentido de la conciencia histórica. No habrá que preocuparse, por consiguiente, tanto de la Génesis como de las Reglas de comportamiento de una sociedad; y lo que permite resolver más fácilmente este problema es el método estructuralista-lingüístico, porque la lengua es una razón humana que tiene sus razones que el hombre no conoce. Armado con esta herramienta metodológica, Lévi-Strauss critica a quienes, con Sartre, se atreven a distinguir entre primitivos y civilizados, al invocar el criterio de la conciencia

\footnotetext{
${ }^{61}$ POPPER,K.: Miseria del historicismo, op. cit.. p. 170.

${ }^{62}$ Ibidem. p. 166.

${ }^{63}$ LÉVI-STAUSS,CL.: El pensamiento salvaje, op. cit., p. 355.
} 
histórica como criterio de demarcación. La Cultura no es reducible a nada anterior, sino que emerge de las profundidades de la inteligencia. La conciencia histórica sólo nos ofrece un esquema a-histórico, abstracto, de hombres haciendo su historia; pero así se sitúa, como los primitivos, ante el eterno pasado: en el Mito. El «mito» en el que se aposenta Sartre no es otro que el del hombre de izquierdas europeo que toma a la Revolución Francesa como mito inaugural: "En efecto, el problema planteado por la Critica de la Razón Dialéctica puede reducirse a éste: ¡en qué condiciones es posible el mito de la Revolución francesa?" ${ }^{64}$. Buscábamos la Razón Dialéctica y nos hemos topado con el Mito. ¿Qué es un hecho histórico? Una abstracción y una selección por parte de la historia.

La historia no es más que un código para la descripción y clasificación cronológica de acontecimientos que reúne en clases de fechas significativas sólo en la medida en que mantienen con las demás relaciones de correlación y de oposición: ordinales (que se encuentra entre esto y aquello), cardinales (distancia entre esto y aquello), relacionales (una fecha respecto de otra fecha), etc. La historia será entendida como propedeútica de las ciencias humanas, a las que suministra los registros desde donde se subsumen y se neutralizan los acontecimientos. Hace falta, pues, (a) salir de la historia, o bien por debajo: la psicología, la fisiología... o bien por arriba: la biología. la geología... (b) O simplemente destruir la historia, considerándola como un Método, y disolviendo la ecuación historia=Humanidad, refugio último de un humanismo trascendental, como si el hombre pudiera recuperar la libertad. La historia. como puro método que es, está desligado del hombre. "El fin último de las ciencias humanas no es constituir al hombre sino disolverlo". La historia tendrá que ser sustituida por el sistema, por un conjunto de operaciones y transformaciones (según las reglas del grupo matemático, o de las álgebras) de sus estados según un código estructural.

Todos los conocimientos, sea de los pueblos ágrafos sea de los pueblos con escritura, están nivelados por una misma Razón que se constituyó en los albores de nuestra separación de la Naturaleza (bajo la regla del Edipo). Esta razón, por lo tanto, no puede ser constituyente de la libertad, de la identidad personal, sino funcional-analítica-constituida. Todas las sociedades tendrían la misma racionalidad (formal y material). Por tanto, hay que descubrir esas «construcciones mentales», esas «leyes universales del espíritu» que descansan en ciertos mecanismos cerebrales. Los componentes de esa razón. los rasgos culturales universales y comunes a todas las culturas: familia, ceremonias... estarían distribuidos por entre las distintas culturas, cada una de las cuales se desarrolla según transformaciones de tipo algebraico -o más groseramente. a modo de un caleidoscopio ${ }^{65}$-, que van trasformando esos rasgos; pero, en cualquier caso, todas las culturas quedan niveladas, con lo que se sustancializa fuertemente el concepto de Cultura, cuya condición -que no

\footnotetext{
${ }^{64}$ Precisamente el hecho «histórico» que hemos tomado nosotros como inicio de la reflexión histórica y que hemos localizado en un comentario de Kant.

${ }^{65}$ LÉVI-STRAUSS,CL.: "L ección inaugural en el Collège de France" en Antropología Estructural, ed. Siglo XXI, México, 1979.
} 
causa- de posibilidad se remitiría a la existencia de infraestructuras. Las diferencias entre las culturas estaría en relación directa a las estrategias con las que se controla a la naturaleza y a los otros hombres. Pero el único nivel «real» será para LéviStrauss, el de la Comunicación. Ahora bien, como señala Ranch ${ }^{66}$ : "La inteligibilidad de las estructuras se encuentra en momentos anteriores, que no sólo serán las razones de las estructuras sociales práctico-inertes sino también las razones de la historia misma, tanto de las organizaciones sociales como de los cambios y transformaciones de esas organizaciones" $i O$ es que acaso Lévi-Strauss no nos remite a un tiempo, el nuestro. que ha conseguido conectar con el de los primitivos? "Este tiempo se nos ha restituido hoy. gracias al descubrimiento de un universo de la información en el que reinan de nuevo las leyes del pensamiento salvaje ${ }^{\text {"67}}$. Pero nos parece totalmente arbitrario suponer que hemos accedido a este mundo de la Información -que supone el descubrimiento del electromagnetismo, la lógica, la teoría de circuitos, la cibernética, etc.. etc.,-- mediante un simple giro del caleidoscopio.

\section{El «fin de la historia»}

Lo que nos ha sorprendido del artículo de Fukuyama ha sido la doble rectificación: la rectificación del modelo combinatorio, porque en su análisis ha utilizado escalas adecuadas. Las totalidades atributivas que ha desplegado han sido las grandes formaciones políticas que entran en conflicto: Antiguo Régimen, Fascismo, Comunismo, Liberalismo, Nacionalismo, Fundamentalismo, que se definen por su vinculación con el «Estado», que es la categoría que las articula. y no, v. gr., el «individuo» o la «familia». De la misma manera ha rectificado el modelo porfiriano: en la «lucha» que han mantenido, una de ellas ha vencido, no por superioridad ideológica, por convencimiento, por bondad o porque se adecua mejor a la naturaleza humana, sino por la violencia en cl caso del Antiguo Régimen o los Fascismos, y por la estrategia económica en el caso del comunismo, a la vez que absorbe los Fundamentalismos (por la Fuerza si es preciso) y Nacionalismos. Sobre esta totalidad atributiva «distribuye» el valor con el que ha logrado vencer: no la emancipación del hombre, no la salida de la alienación, no la libertad, no la identidad personal, sino el uso, aun cuando triste. aburrido o melancólico, de la técnica.

Lo que nos ha sorprendido es el análisis gnoseológico puro de Fukuyama, sin eufemismos y sin disimulos. La legitimación descarnada del nuevo orden que se nos augura está propuesta. ¿Podemos hablar entonces del «fin de la historia»? Es decir, ¿son «despreciables» -en el sentido en que lo son ciertas magnitudes de la física que no afectan al resultado final- todos esos movimientos africanos, asiáticos, hispanoamericanos... que bullen todavía de manera amorfa? No lo sabemos aún. Por eso habrá quien hable de «final de la historia»; habrá quien considere mejor el «fin de una guerra», la que comenzó quizá con la «Guerra de los Treinta Años»; y habrá

\footnotetext{
${ }^{66}$ RANCH,E.: El método dialéctico en Jean-Paul Sartre, Unjversidad de Alicante, 1983, p. 431.

${ }^{67}$ LÉVI-STRAUSS.CL..: El Pensamiento salvaje. op. cit., p. 387.
} 
quien espere que la historia no ha hecho ya sino comenzar. Será conveniente releer otra vez el artículo de Fukuyama. 